\title{
David Oliver: Should practical quality improvement have parity of esteem with evidence based medicine?
}

\author{
David Oliver consultant in geriatrics and acute general medicine
}

Berkshire

As I qualified in 1989, my career has coincided with the growing evidence based medicine movement. It's been a major advance in evaluating clinical interventions, defining best practice, and moving beyond a reliance on expert opinion or tradition. It's given us methodologically consistent systematic reviews such as Cochrane, and evidence based guidelines such as those from NICE. ${ }^{1-3}$

Medics learn that good systematic reviews and meta-analyses top the evidence pyramid, then randomised controlled trials (RCTs). ${ }^{45}$ In conventional evidence based medicine, even good local observational and implementation data are ranked as less weighty evidence. This may skew our world view-making it harder for quality improvement (QI) work to find academic funding, prestige, or publication impact.

For years I extensively researched in-hospital fall prevention. ${ }^{6}$ I concluded in systematic reviews (as did Cochrane and NICE) ${ }^{78}$ that only a modest reduction in fall rates could be demonstrated in RCTs. This is partly due to the relatively short duration of interventions, which may need longer to be adopted and embedded. In RCT methodology, interventions are pre-specified in the study protocol, leaving no leeway to ditch, add, or refine elements during the trial. And the actions and engagement of frontline practitioners and the real world context in which they work are critical to success.

I've since realised that hospital teams are far more interested in implementing and evaluating practical interventions to reduce falls in their own wards than in peer reviewed trial data; likewise with reducing other common harms, errors, or safety incidents. Bigger effects are sometimes described in organisations using QI work where local teams design, implement, modify, and measure pragmatic interventions in real time.

QI can deliver tangible outcomes more quickly than RCTs or take as long as needed to assess benefit, with no fixed endpoint

QI is equally relevant to a range of interventions to improve processes and outcomes in health services or indeed for testing in the context of local systems - the implementation of evidence based best practice from reviews and guidelines.

QI can deliver tangible outcomes more quickly than RCTs or take as long as needed to assess benefit, with no fixed endpoint. It has a methodological and theoretical rigour and peer community of its own. ${ }^{9}{ }^{10}$ Ethical approval is less burdensome. With training, local leaders, and data analytics support, it can be delivered by teams who aren't career academics or based in research institutions.

QI is always open to the charge that local findings aren't externally generalisable or the findings reproducible-but then so are RCTs. But a compelling weight of evidence can emerge, as interventions are disseminated and adopted more widely.

Shouldn't we start giving QI work equal status to evidence based medicine, given its powerful ability to tackle pressing and relevant problems in individual systems and services in real time?

Competing interests: See www.bmj.com/about-bmj/freelancecontributors/david-oliver.

Provenance and peer review: Commissioned; not externally peer reviewed.

Follow David on Twitter: @mancunianmedic

Rycroft-Malone J, Fontenla M, Bick D, Seers K. A realistic evaluation: the case of protocol-based care. Implement Sci 2010;357:38. doi:10.1186/1748-5908-5-38. https:/ 20504293

2 University of Canberra. Evidence-based practice in health. Apr 2017. http://canberra. libguides.com/c.php?g=599346\&p=4149721.

3 Blunt CJ. London School of Economics and Political Science. Hierarchies of evidence in evidence-based medicine. Sept 2015. http://etheses.Ise.ac.uk/3284/1/Blunt heirachies of evidence.pdf.

4 BMJ Clinical Evidence. What is GRADE? Sept 2012. http://clinicalevidence.bmj.com/x/ set/static/ebm/learn/665072.html.

5 Essential Evidence Plus. Levels of evidence. https://www.essentialevidenceplus.com/ product/ebm loe.cfm?show=grade.

6 Oliver D, Healey F, Haines TP, Ganz D, Rubenstein R, eds. Preventing falls and fall-related injuries in hospitals. Clin Geriatr Med 2010;357:645-92. doi:10.1016/i.cger.2010.06.005. www.sciencedirect.com/science/journal/07490690/26. pmid:20934615.

7 National Institute for Health and Care Excellence. Falls in older people: assessing risk and prevention. Jun 2013. https://www.nice.org.uk/guidance/cg161. 
8 Cameron ID, Gillespie LD, Robertson MC, et al. Interventions for preventing falls in older people in care facilities and hospitals. Cochrane Database Syst Rev 2012;357:CD005465. doi:10.1002/14651858.CD005465.pub3. pmid:23235623.

9 Health Foundation. Quality improvement made simple: what everyone should know about healthy care quality improvement. Aug 2013. www.health.org.uk/sites/health/files/ QualitylmprovementMadeSimple.pdf.
10 Health Foundation. Q. A connected community working together to improve quality in health and care across the UK. https://q.health.org.uk/.

Published by the BMJ Publishing Group Limited. For permission to use (where not already granted under a licence) please go to http://group.bmj.com/group/rights-licensing/ permissions 